\title{
Influences of Project Management Capabilities on the Organizational Performance of the Saudi Construction Industry
}

\author{
Hassan Ahmed Sulieman \\ Faculty of Engineering, Civil Engineering Department, \\ Northern Border University, Arar, Saudi Arabia \\ hassan.abdualrahman@nbu.edu.sa
}

\author{
Faris Abdulaziz Alfaraidy \\ Faculty of Engineering, Civil Engineering Department, \\ Northern Border University, Arar, Saudi Arabia \\ falfaraidy@nbu.edu.sa
}

\begin{abstract}
This paper aims to study the relations between construction enterprises' project management capabilities and organizational performance. A questionnaire survey was administered to 89 Saudi construction contracting organization administrative members. Data were obtained from 32 projects that were held during the last two years and were analyzed using structural equation modeling (SEM). It was hypothesized in this study that a construction organizational performance is influenced by project management capabilities within the enterprise. A structural equation model was set up to measure the above two latent variables through their constituent variables. This study introduced a method to measure performance both in qualitative and quantitative terms. The strong path coefficients between the constructs of the model are an indication that after decades in pursuit of finding ways to improve the performance of construction organizations, subjective dimensions of performance have proven to be as effective as the traditional objective dimensions.
\end{abstract}

\section{Keywords-balanced scorecard; performance; SEM}

\section{INTRODUCTION}

Saudi Arabia is the largest oil exporter in the world. As a result, the Saudi economy is constantly on the rise and the construction sector's activity is increasing. The construction industry plays a key role in the performance of all economic sectors. The Saudi government has supported construction projects through substantial investments in infrastructure projects. The problem of poor performance in construction projects is a global phenomenon and the construction industry in Saudi Arabia is no exception [1]. Performance measurement has new methods that can measure financial and non-financial aspects [2]. These frameworks vary according to the place of application, and whether they are for organizations, projects, or stakeholder performance [3]. It is known that project management through integrated and balanced indicators will achieve a significant improvement in the performance and future of an industry. Performance measurement and management are still unused as a performance improvement tool in the Saudi Arabia construction industry. The objective of this research is to study the relations between construction organization's project capabilities and organizational performance based on strategic measures, not only financial which are traditionally used in most construction organizations.
The essence of these measurements is modified and they are being pushed from accounting-based towards an economicoriented framework. Considering nowadays business and the global economic impact of the construction industry, performance management and measurement in construction is important and critical. Therefore, effective construction project management is crucial for higher performance levels $[4,5]$.

\section{LITERATURE REVIEW}

The proposed framework consists of an integrated and balanced system for measuring and managing the organization's project capabilities in term of its ability to address all performance management stages and balanced scorecard (BSC) elements. Public and private enterprises are gradually moving towards the adoption of the performance management system (PMS) as it provides an integrated and coherent range of human resources processes which can be supportive in terms of contributing to the overall improvement of organizational and individual performance [6]. The sophistication of strategic project management is a function of the organization's level of relevant resources, competencies, and capabilities. These influence the propensity for learning, the characteristics and context that impact required strategic implementation and strategic outcome realized through strategic project management [7].

\section{A. Project Management Capabilities}

Project management capabilities include management capabilities regarding research and development, health and safety, schedule [8], cost, quality, knowledge, risk, supply chain, and human resources. Research and development capability is a response to increased industry requirements that occurred as a result of globalization and competition. Developments occur in all phases of the construction process and technologies that are deemed to have a positive impact on competitive advantage emerge. It is a major enabler of the project to complete on time by the use of a series of processes. These processes are activity definition, sequencing, resource estimating, duration estimating, schedule development and schedule control [9]. Cost management activities include planning, estimating, budgeting, and controlling of the project [9]. Quality management refers to the activities in an organization that determine quality policies, objectives, and 
responsibilities and represents solutions in response to the complex and non-standardized nature of construction projects. Even minor defects may require re-construction and may impair the facility's operations parties [10]. It has a strong correlation with project performance. Knowledge management is essential in accessing information relevant to best practices, lessons learned, historical and schedule data, and any other information necessary to run a project efficiently [11]. The capability of an organization to cope with sophisticated projects is the result of successful knowledge management [12]. Health and safety management has a human dimension as accidents during the construction process can result in personal injuries and cause an increase in indirect costs such as the cost of insurance, inspection, and conformance to regulations [13].

\section{B. Organization Performance}

The balanced scorecard (BSC) perspective was adopted in this study to measure organization performance because of its established status and its common use. It is a framework for measuring the strategic, operational and financial characteristics of an enterprise. It combines four perspectives to assess the performance of an organization. The financial perspective indicates the success of the enterprise measured in terms of indicators such as profitability. The financial performance measures indicate whether the enterprise's strategy, implementation, and execution are contributing to the bottom-line improvement. The financial objectives reflect the financial performance expected from the strategy and also serve as the ultimate targets for objectives and measures of all the other scorecard perspectives. Measures of financial performance of an organization are important in the reduction of risk but overemphasis on it leads to an unbalanced situation with regard to other perspectives [14]. Organizations that really benefit from a scorecard process would inevitably move the focus of their attention to the non-financial scorecard metrics [15]. It is understandable that overemphasis on short-term financial results can cause enterprises to overinvest in shortterm fixes and to underinvest in long-term value creation [16]. The learning and growth perspective refers to the progress achieved by an enterprise and its growth potential. Organizational learning capacity and the achievements of the enterprise in areas such as the enterprise's image or various competencies are also taken into account in this perspective. The learning and growth perspective of the BSC identifies the infrastructure that the organization must build to create longterm growth and improvement. The predominant element within this perspective is whether the organization possesses the required capabilities to improve and create future value for its stakeholders [17]. The internal business perspective is an indicator of the success and efficiency of operational and managerial activities in the organization. Through the use of $\mathrm{BSC}$, the key processes in an organization are monitored to ensure that outcomes will be satisfactory and thus this perspective serves as a mechanism through which performance expectations of both customers and enterprise are achieved. It is further argued that this perspective reveals two fundamental differences between the traditional and BSC approaches to performance measurement. The traditional approaches attempt to monitor and improve existing business processes whereas the BSC approach identifies entirely new processes at which the organization must excel to meet customer and financial objectives [17]. The customer perspective considers the satisfaction of the different participants in the project such as clients and end users. How an organization is performing through the eyes of its customers has become a priority for business managers and this perspective captures the ability of the organization to provide quality goods and services and achieve overall customer satisfaction [17]. Leaders in the service industry are good at meeting customer requirements and performance measurement [18]. The core outcome measures include customer satisfaction, customer retention, average customer duration, loyalty, repeated businesses, customer claims, complaints, customer profitability, annual income per customer, short lead times, new customer acquisition, delivery on time, and market and account share in targeted segments [19].

\section{RESEARCH METHODOLOGY}

Hypothetical relationships with proposed measures and indicators were set based on literature, consultation of professionals and previous studies, consisting of two latent variables and 13 constituent variables. Then a questionnaire consisting of performance measures and indicator related questions was designed in Likert scale. Data were collected from Saudi Arabia construction organizations through 89 respondents which were randomly selected from the top to medium level staff of the organizations. Influences on organizational performance were analyzed using SEM. All the stages of the research methodology are presented in Figure 1.

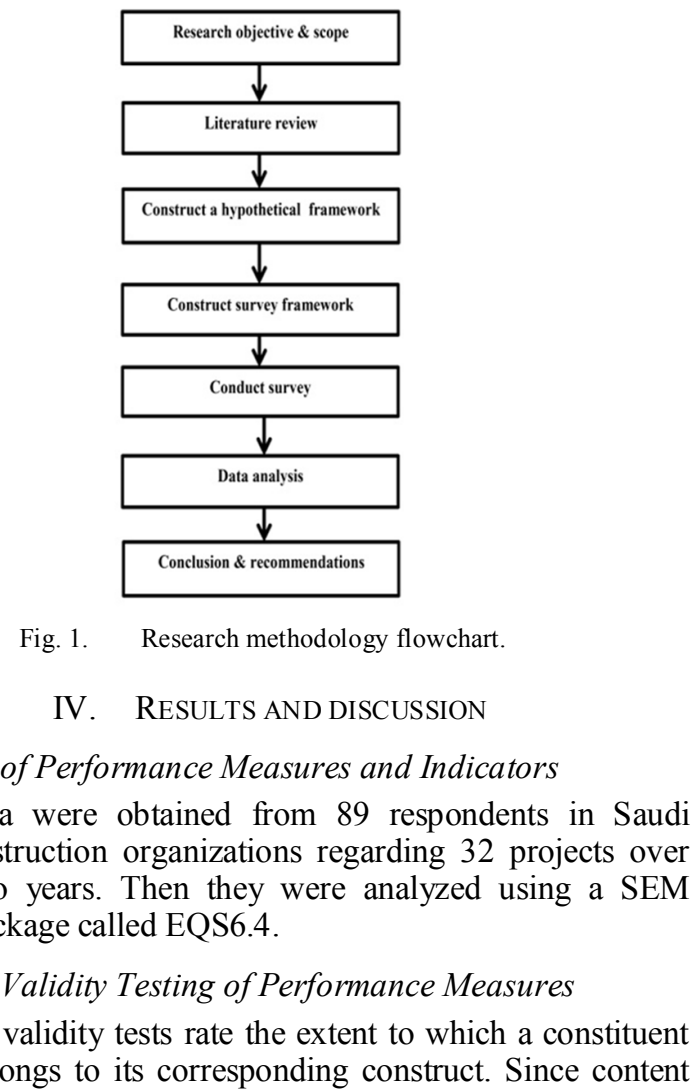


validity cannot be tested by using statistical tools, an in-depth literature survey is necessary to keep the researcher's judgment on the right track [20]. An extensive literature survey was conducted to specify the variables that define latent variables.

\section{2) Scale Reliability Testing of Performance Measures}

The scale reliability is the internal consistency of a latent variable and is measured most commonly with a coefficient called Cronbach's alpha. The purpose of testing the reliability of a construct is to understand how each observed indicator represents its correspondent latent variable. According to the analysis results, as seen in Table I, Cronbach's alpha values were 0.787 for project management capabilities and 0.846 for organization performance. These reliability values are satisfactory since the Cronbach's alpha coefficients are all above 0.70 , which is the recommended value [21].

TABLE I. CRONBACH'S ALPHA

\begin{tabular}{|c|c|}
\hline Latent variable & Cronbach's alpha \\
\hline Project management capabilities, $\Phi$ & 0.787 \\
\hline Organization performance, $\gamma$ & 0.846 \\
\hline
\end{tabular}

\section{3) Convergent Validity Testing of Performance Measures}

Convergent validity is the extent to which the latent variable correlates to corresponding items designed to measure it. Ideally, convergent validity is tested by determining whether the items in a scale converge or load together on a single construct in the measurement model. If the factor loadings are statistically significant, then convergent validity exists. Since sample size and statistical power have a substantial effect on the significance test, this statement needs expanding [20]. The model parameters were assessed and all factor loadings were found to be significant at $(\alpha=0.05)$ as in Tables II-III.

TABLE II. FACTOR LOADING OF ORGANIZATION PROJECT MANAGEMENT CAPABILITIES

\begin{tabular}{|c|c|}
\hline Project management capabilities, $\Phi$ & Factor loadings \\
\hline Human resources management, $\beta_{1}$ & 0.625 \\
\hline Cost management, $\beta_{2}$ & 0.934 \\
\hline Quality management, $\beta_{3}$ & 0.852 \\
\hline Schedule management, $\beta_{4}$ & 0.682 \\
\hline Risk management, $\beta_{5}$ & 0.789 \\
\hline Supply chain management, $\beta_{6}$ & 0.694 \\
\hline Health \& safety management, $\beta_{7}$ & 0.199 \\
\hline Knowledge management, $\beta_{8}$ & 0.885 \\
\hline Research \& development, $\beta_{9}$ & 0.855 \\
\hline
\end{tabular}

\section{4) Discriminant Validity Testing of Performance Measures}

Discriminant validity is the extent to which the items representing a latent variable discriminate that construct from other items representing other latent variables. This is particularly important when constructs are highly correlated and similar in nature. In essence, items from one scale should not load or converge too closely with items from a different scale.

TABLE III. FACTOR LOADING OF ORGANIZATION PERFORMANCE

\begin{tabular}{|c|c|}
\hline Organization performance, $\boldsymbol{\gamma}$ & Factor loadings \\
\hline Financial perspective, $\mu_{1}$ & 0.485 \\
\hline
\end{tabular}

\begin{tabular}{|c|c|}
\hline Internal business perspective, $\mu_{2}$ & 0.499 \\
\hline Learning \& growth perspective, $\mu_{3}$ & 0.769 \\
\hline Customer perspective, $\mu_{4}$ & 0.686 \\
\hline
\end{tabular}

\section{B. Structural Model Analysis}

The SEM steps are: (1) Specification of the model, (2) estimation and identification of the model, and (3) evaluation of the model fit. The analysis of the model performance is explained below.

\section{1) Specification of the Model}

Literature review and expert interviews were conducted to develop a conceptual model that shows how the latent variable "resources and capabilities" affects organizational performance. The model prepared for this purpose assumed that "resources and capabilities", influences the "organization performance". This model is specified by the direct path equation (1):

$$
\gamma=\mathrm{b} \Phi+\mathrm{c}
$$

where, $\gamma=$ organization performance, $\Phi=$ project capabilities, $\mathrm{b}=$ path coefficient, and $\mathrm{c}=$ error term.

\section{2) Estimation and Identification of the Model}

It means that it is theoretically possible for the computer to derive a unique estimate of every model parameter. Different types of structural equation models must meet certain requirements in order to be identified. If a model fails to meet the relevant identification requirements, the attempts to estimate it may be unsuccessful. There are several methods of model estimation. Some frequently utilized methods include maximum likelihood (ML), generalized least squares (GLS), asymptotically distribution-free (ADF) estimator and robust statistics.

\section{3) Evaluation of the Model Fit}

It means to determine how well the model as a whole explains the data. Once it is determined that the fit of a structural equation model to the data is adequate, the performance measurement model is completed. However, it seems that the concern for overall model fit is sometimes so great that little attention is paid to whether estimates of its parameters are actually analyzed. The model fit indices for each construct were assessed through the non-normed fit index (NNFI), comparative fit index (CFI), the root mean square error of approximation (RMSEA) and the ratio of $\chi 2$ per degree of freedom (dof). Model fit indices analysis results for each construct can be seen in Figure 2 and Table IV. Within the structural model illustrated in Figure 2, for every unit "project management capabilities" that goes up, "organization performance" rises. Moreover, the influence of measures and indicators of project management capabilities on organization performance indicators can also be analyzed mathematically as:

$$
\beta_{1} \times 0.617 \times 0.542=0.735 \times \mu_{1}
$$

The perspective values in term of measures and indicators are listed in Table V. 


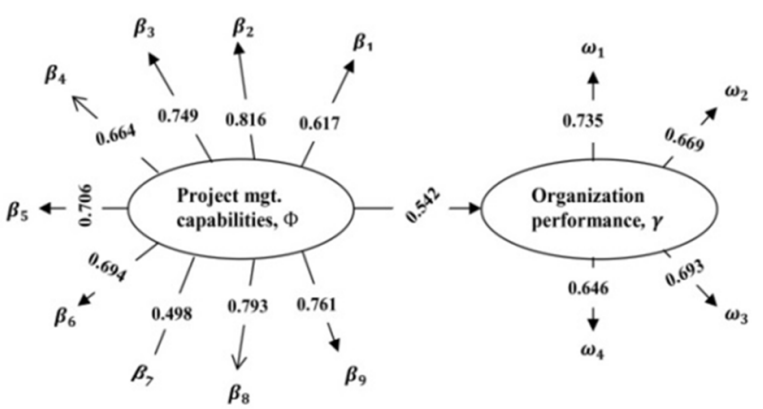

Fig. 2. Influence of project management capabilities to organizational performance

TABLE IV. MODEL FIT INDICES FOR PROJECT MANAGEMENT CAPABILITIES TO ORGANIZATION PERFORMANCE

\begin{tabular}{|c|c|c|}
\hline Fit indices & Allowable range & Overall \\
\hline NNI & 0 (no fit)-1 (perfect fit) & 0.792 \\
\hline CFI & 0 (no fit)-1 (perfect fit) & 0.819 \\
\hline RMSEA & $<0.1$ & 0.094 \\
\hline$\chi 2 /$ dof & $<3$ & 1.864 \\
\hline
\end{tabular}

TABLE V. VALUES OF PERSPECTIVES IN TERMS OF MEASURES

\begin{tabular}{|c|c|c|c|}
\hline$\mu_{1}$ & $\mu_{2}$ & $\mu_{3}$ & $\mu_{4}$ \\
\hline $0.455 \times \beta_{1}$ & $0.500 \times \beta_{1}$ & $0.483 \times \beta_{1}$ & $0.518 \times \beta_{1}$ \\
\hline $0.602 \times \beta_{2}$ & $0.661 \times \beta_{2}$ & $0.638 \times \beta_{2}$ & $0.685 \times \beta_{2}$ \\
\hline $0.552 \times \beta_{3}$ & $0.607 \times \beta_{3}$ & $0.586 \times \beta_{3}$ & $0.629 \times \beta_{3}$ \\
\hline $0.490 \times \beta_{4}$ & $0.538 \times \beta_{4}$ & $0.519 \times \beta_{4}$ & $0.557 \times \beta_{4}$ \\
\hline $0.521 \times \beta_{5}$ & $0.572 \times \beta_{5}$ & $0.552 \times \beta_{5}$ & $0.592 \times \beta_{5}$ \\
\hline $0.512 \times \beta_{6}$ & $0.562 \times \beta_{6}$ & $0.543 \times \beta_{6}$ & $0.582 \times \beta_{6}$ \\
\hline $0.367 \times \beta_{7}$ & $0.403 \times \beta_{7}$ & $0.390 \times \beta_{7}$ & $0.418 \times \beta_{7}$ \\
\hline $0.585 \times \beta_{8}$ & $0.642 \times \beta_{8}$ & $0.620 \times \beta_{8}$ & $0.665 \times \beta_{8}$ \\
\hline $0.561 \times \beta_{9}$ & $0.617 \times \beta_{9}$ & $0.595 \times \beta_{9}$ & $0.639 \times \beta_{9}$ \\
\hline
\end{tabular}

\section{CONCLUSION}

Globalization brought on construction enterprises augmented capacity, project management capabilities, expanded market areas, a variety of projects, and improved competitivity. Performance management of organizations became an important subject of interest during the last decades. The proposed performance measurement tool extrapolates the project management capabilities that the organization will need to innovate and enhance its "learning \& growth", "financial issues", and "internal business", which lead to "customer satisfaction". This study introduced a method to measure performance in qualitative and quantitative terms. The strong path coefficients between the constructs of the model are an indication that after decades in pursuit of finding ways to improve the performance of construction organizations, subjective dimensions of performance have proven to be as effective as the traditional objective dimensions.

\section{REFERENCES}

[1] N. M. A. Abbas, "The Impact of construction contractsmodels on construction claims in the Saudi Arabia", $14^{\text {th }}$ Annual ARCOM Conference, Reading, UK, September 9-11, 1998

[2] A. Neely, B. Marr, G. Roos, S. Pike, O. Gupta, "Towards the Third Generation of Performance Measurement", Controlling, Vol, 15, No. 34, pp. 129-136, 2003
[3] H. Yang, J. F. Yeung, A. P. Chan, Y. Chiang, D. W. Chan, "A critical review of performance measurement in construction", Journal of Facilities Management, Vol. 8, No. 4, pp. 269-284, 2010

[4] Z. Jin, F. Deng, H. Li, M. Skitmore, "Practical Framework for Measuring Performance of International Construction Firms", Journal of Construction Engineering and Management, Vol. 139, No. 9, pp. 11541167, 2013.

[5] H. S. Robinson, P. M. Carrillo, C. J. Anumba, A. M. A-Ghassani, "Review and implementation of performance management models in construction engineering organizations", Construction Innovation, Vol. 5, No. 4, pp. 203-217, 2005

[6] A. Jugmohun, "Factors that influence the effectiveness of performance management system adoption in organization", Global Journal of Human Resources Management, Vol. 6, No.1, pp. 51-66, 2018

[7] J. Brathwaite, "A contemporary twist on capability enhancement: how strategic project management influences capabilities requirements relationship with strategic outcomes", The Business and Management Review, Vol. 9, No. 4, pp. 574-591, 2018

[8] C. Hendrickson, T. Au, Project Management for Construction, Prentice Hall, 1989

[9] Project Management Institute, A Guide of Project Management Body of Knowledge (PMBOK), Project Management Institute, 2017

[10] G. K. Kanji, A. Wong, "Quality culture in construction industry", Total Quality Management, Vol. 9, No. 4, pp.133-140, 1998

[11] J. M. Kamara, G. Augenbroe, C. J. Anumba, P. M. Carrillo, "Knowledge management in the architecture, engineering and construction industry", Construction Innovation, Vol. 2, No. 1, pp. 53-67, 2002

[12] A. Warszawski, "Strategic planning in construction companies", Journal of Construction Engineering and Management, Vol. 122, No. 2, pp. 133140,1996

[13] K. Ringen, J. Seegal, A. Englund, "Safety and health in the construction industry", Annual Review of Public Health, Vol. 16, pp. 165-188, 1995

[14] J. Liebowitz, C. Y. Suen, "Developing knowledge management metrics for measuring intellectual capital", Journal of Intellectual Capital, Vol. 1 , No. 4, pp. 54-66, 2000

[15] A. M. Schneiderman, "Why balanced scorecards fail?", Journal of Strategic Performance Measurement, Special Edition, pp. 6-11, 1999

[16] R. S. Kaplan, D. P. Norton, The Balanced Scorecard: Translating Strategy into Action, Harvard Business Review Press, 1996

[17] D. Amaratunga, D. Baldry, M. Sarshar, "Assessment of facilities management performance - what next?", Facilities, Vol. 18, No. 1-2, pp. $66-75,2000$

[18] A. Robson, V. B. Prabhu, "What can we learn from leading service practitioners about business excellence?", Managing Service Quality, Vol. 11, No. 4, pp. 249-261, 2001

[19] S. McCabe, Benchmarking in Construction, Blackwell Science, 2001

[20] S. C. Dunn, R. F. Seaker, M. A. Waller, "Latent variables in business logistics research: scale development and validation", Journal of Business Logistics, Vol. 15, No. 2, pp. 145-172, 1994

[21] J. Nunnally, Psychometric Theory, McGraw-Hill, 2010 